\section{CARBON AND CARBON-COMPOUNDS}

THE wayward and inconstant train of coloured lightbands that spectroscopists have noted and distinguished in the spectra of various carbon-compounds in flames and gas-vacuum tubes are as yet far from having all received their full and appropriate interpretations. The extent to which they abound as impurities in almost all spectral vacuum-tubes is a common observation, and in a survey of this kind, aiming at no systematic exploration, of a variety of end-on vacuum-tubes in the large and perfect spectroscope erected by Prof. Piazzi Smyth for the examination of auroræ, I have had from time to time, at his kind invitation, excellent opportunities for discriminating some of the component groups and clusters of the carbon-denoting series from each other pretty clearly.

Among the least alterable and changeful in its appearance of these coloured ranks is the five-tongued spectrum of wedge-like bands best seen in the end-on prismatic view of a coal-gas blow-pipe flame. Its bands have shaft-lines at the edge and on their fading slopes, with the exception of the last or violet one, just including within its bright edge the solar line of Fraunhofer's spectrum, $\mathrm{C}_{\text {. }}$. This has a fine-line precursor, nearly coincident with $\mathrm{H} \gamma$, and a faint haze-band preceding it. Close to the place of $b_{1}$ in the solar spectrum appears the bright edge or chief shaft-line of the green band, fitly styled the "green giant," as it is the real Anak of the coal-gas flamespectrum. Its less refrangible similitudes in the yellowgreen and orange-red are quite subordinate groups, the latter being only discernible in spectroscopes of large aperture and of very great transparency. The fifth finger of this spectral gauntlet is a blue band, or quintett of five close lines pretty equally spaced and pretty equal in brightness, with little haze between them, lying once or twice its own breadth on the more refrangible side from $\mathrm{H} \beta(\mathrm{F}$.$) . The frontispiece of Watt's "Index of Spectra"$ contains a figure of this spectrum; and wave-length positions and symbols and descriptions of its groups are given in the body of the work, under the title "Carbon, Spectrum I." $a, \gamma, \delta, \epsilon, f$ ( $\beta$ and $\eta$ carent) are the five familiar potentates of the blow-pipe flame; but the two line-bands $\zeta, \theta$, one on each side of $f$, added in the figure and in the text of Watt's "carbon-spectrum I.," are not visible in the blow-pipe flame-spectrum. Along with a similar ultra-violet cluster just following $\mathrm{H} \mathrm{K}$ in the solar spectrum, they form a triumvirate, the spectral origin of which Professors Liveing and Dewar have recently affirmed to be cyanogen. A reason to question the correctness, however, of Messrs. Liveing's and Dewar's surmise presented itself to me in my examination of the cnd-on tubes by the spectacle of the six-lined violet cluster $\theta$ rearing itself, without any accompaniment of its blue associate $\zeta$, into extraordinary magnificence in a Marsh-gas tube. The grey or ultra-violet member of the trio was indeed weakly discernible at the same time; and in just this relative brightness and condition of extreme isolation from every other spectral feature I have recently observed these two violet and ultra-violet line-clusters in the blue flame part of the arc between particularly pure carbon poles in the Brush's or Anglo-American Company's electric light.

Another reason for suspecting multiplicity of form in the carbon-spectrum by itself occurred to me in an examination of the spectrum of cyanogen in an end-on tube. A perfect counterpart, it is well known, of the blow-pipe flame spectrum is producible by the inductionspark in vacuum-tubes of olefiant gas. Accompanying it however is another spectrum which in its fullest purity and intensity is equally well known to be produced by a weak induction-spark in tubes of carbonic oxide and carbonic acid gas. The blue quintett and the violet Gband are wanting in this spectrum. The edges of the green, citron and orange-red bands are displaced, and these bands are devoid of shaft-lines, being composed entirely of haze and fine linelets which smoothly shade them off. The olefiant gas and "carbonic oxide" spectra mingle together, usually in divers proportions in the carbon-impurities of gas-vacuum tubes.

Two cyanogen tubes (one of them of hardest glass) prepared by M. Salleron betrayed alike only the smallest trace of hydrogen by its red line, when they were lighted up by the induction-coil. Aqueous and atmospheric oxygen may therefore be presumed to have been pretty completely expurgated from these tubes, and the gas which charged them to have been an exceptionally pure compound of nitrogen and carbon. Far brighter, notwithstanding this, than in any other vacuum-tube, the smooth-shaded "carbon-oxide" bands made their appearance; and equally splendid with them was the closeribbed red and yellow fluting forming the less-refrangible part of the spectrum, figured and described by Angstrom and Thalèn as that of "nitric oxide." The coincidence with the same spectrum of the bright cyanogen-tube lines in the blue and violet spectral regions was not closely examined; but as far surpassing in brightness the red-end view of it obtained in any other nitrogen-holding vacuumtube (nitric oxide itself not excepted), the rasp-like ridges of the so-called nitric oxide spectrum were immediately measured with great care and accuracy. Angström's positions and tableau (exactly reproducing that of Plücker and Hittorf) of this region were completely verified; and the discussion of the well-based determinations left no doubt that while a simple order reigns sensibly among the small linelet features of each separate ridge, the ridges have no perceptible connection with each other or with the linelet-intervals upon them in the pitch of their wavefrequencics, although they follow each other closely in a gradually narrowing succession. In the rest of the nitrogen-spectrum, where the ridge-intervals are much wider, it is again not possible to trace between the ridges any simple wave-period connection.

Were I not from these measures, and from the foregoing considerations disposed to regard shaded spectral bands as independent systems of vibration, indicating most probably particular atomic groupings in a molecule, I should have beheld with some surprise the complete and thorough metamorphosis shown me by Mr. Lockyer since the above particulars were noted, which the smooth-banded "carbon-oxide" spectrum undergoes by introducing a condensing-jar, or better, a jar and air-break, into the circuit of the induction-coil. The smooth shadings disappear, the shaft-lines, the "Anak and the sons of Anak" of the olefiant-gas or blowpipe-flame spectrum make their appearance in their place ; even the blue quintett of that spectrum comes forth from its hiding-place ; and, as far as I could examine the spectral appearance of the carbonic-oxide tube in the now condensed discharge with complete precision, the whole blow-pipe flame, or so-called "hydro-carbon" spectrum, is perfectly reproduced. If we cannot admit, as I think that the cyanogen-tube experiment forbids us to do, that a chemical transformation has taken place, then we must acknowledge that among the forms which the spectrum of carbon is capable of assuming, there may, by subdivision of its molecule into separate vibrating systems, exist not one, but as many different "low-temperature" spectra of that Briareus-like, hundredfisted, or Proteus-like, hundred-visaged element, as the electric discharge is capable of dividing its evidently complex gaseous molecule into separate spectroscopically individual groups.

A. S. HERSCHEL

\section{PHYSICS WITHOUT APPARATUS}

I.

$\mathrm{T}^{\mathrm{T}}$ is almost a proverb in science that some of the greatest discoveries have been made by the most simple means. It is equally true that almost all the 